\title{
O "POLVO": O TROCADILHO A SERVIÇO DA CRÍTICA EM CAPAS DA REVISTA VEJA
}

\author{
Ilana da Silva Rebello VIEGAS \\ Universidade Federal Fluminense \\ ilanarebello@uol.com.br
}

Resumo: Pensando no ensino de língua portuguesa, este trabalho tem por objetivo apresentar uma leitura crítica do gênero capa de revista, analisando como a Veja, por meio da caricatura e da palavra, (do trocadilho e da imagem) legitima e veicula seu discurso ideológico e constrói sentidos para atrair o público consumidor. Para tanto, analisa-se três capas disponíveis na internet, baseando-se, sobretudo na teoria Semiolinguística de Análise do Discurso, articulando esses postulados aos pressupostos da Linguística Textual. Para a análise do texto não-verbal, busca-se respaldo em noções da Semiótica Peirceana. Os resultados obtidos nessa análise serão objeto de aplicação pedagógica em aulas de língua portuguesa.

Palavras-chave: Semiolinguística. Semiótica Peirceana. Capas de revista. Trocadilho. Ensino de língua portuguesa.

Abstract: While thinking about the teaching of the Portuguese language, this paper aims at presenting a critical reading of the magazine cover genre, by analyzing how Veja, through the use of wordplay and image, legitimates and displays its ideological discourse and creates meanings to attract consumers. Thus, three magazine covers available at the internet are analyzed in the light of the theory of Semiolinguistic of Discourse Analysis, articulating those postulates to presuppositions of Text Linguistics. For the analyses of the nonverbal text, notions of Peircean Semiotics are used. The findings of this analysis will be the object of pedagogical application in Portuguese language classes.

Keywords: Semiolinguistic. Peircean Semiotics. Magazine cover. Wordplay. Teaching of the Portuguese.

\section{Introdução}

Apesar de o avanço tecnológico ter permitido o crescimento das redes de comunicação, a arte de comunicar ainda é um desafio na nossa sociedade. Os gêneros já consagrados têm tomado formatos diferentes em função não só das novas necessidades como também dos múltiplos recursos tecnológicos disponíveis. As revistas informativas, como toda produção midiática, cujo 
objetivo principal é a informação, acompanham as novas tendências expressivas. Não basta só informar, é preciso trabalhar essa informação de forma criativa a fim de que o leitor se interesse e compre a revista. Dessa forma, ser apenas objetivo não é suficiente para atrair o leitor.

\section{0 contrato de comunicação entre sujeitos}

Na teoria Semiolinguística de Análise do Discurso, Charaudeau (2001: 31 2) mostra que todo ato de linguagem é uma encenação que comporta quatro protagonistas, sendo dois situacionais, externos e dois discursivos, internos. Os sujeitos "externos" são o EUc (eu-comunicante) e o TUi (tu-interpretante) e os sujeitos "internos", o EUe (eu-enunciador) e o TUd (tu-destinatário).

No circuito externo, os seres são de ação, instituídos pela produção $(E U c)$ e pela interpretação (TUI) e guiados pelo FAZER da situação psicossocial. Já no circuito interno, os seres são da fala, instituídos pelo DIZER (EUe e $T U d$ ).

\begin{tabular}{|c|c|c|}
\hline \multirow{4}{*}{$\begin{array}{l}\text { EUcTUi } \\
\qquad \downarrow \downarrow \\
\text { jornalista }\end{array}$} & Fazer-Situacional & \multirow{4}{*}{ leitor real } \\
\hline & circuito interno - DIZER & \\
\hline & $\begin{array}{l}\quad \text { EUe } \leftarrow \text {----------- } \rightarrow \text { TUd } \\
\quad \downarrow \downarrow \\
\text { emissor interlocutor } \\
\text { (a identidade } \\
\text { que o jornalista } \\
\text { assume no texto) }\end{array}$ & \\
\hline & $\begin{array}{c}\text { circuito externo - FAZER } \\
\text { Mundo psicossócio-cultural } \\
\text { Relação Contratual }\end{array}$ & \\
\hline
\end{tabular}

Dessa forma, todo ato de linguagem, seja ele falado ou escrito, é uma representação comandada pelos sujeitos externos e internos. Charaudeau chama essa representação de mise en scène.

No ato de comunicação, o sujeito comunicante tem por objetivo significar o mundo, a partir de seus propósitos, para um sujeito interpretante. Em relação ao texto jornalístico, Charaudeau (2006, p. 256) afirma que 
(...) o cidadão nunca tem acesso ao acontecimento bruto, ele sempre entra em contato com um acontecimento filtrado pela mídia. Assim, ora o acontecimento bruto e acontecimento veiculado pela mídia se confundem, ora um prepondera sobre o outro, criando um círculo vicioso (...)

Ao comprar uma revista, a informação que o leitor tem do fato é aquela fornecida pelo jornalista. Nesse sentido, se o leitor não estiver atento, pode interpretar um fato, por exemplo, a partir da maneira pela qual ele é mostrado pela revista. As palavras e as imagens apresentadas podem ou não coincidir com a realidade, podem ou não estar manipuladas.

Assim, no processo de transação, para proceder a uma análise do texto, o sujeito interpretante precisa não só mobilizar o sentido das palavras e suas regras de combinação como também construir um sentido que corresponda a sua intencionalidade. Nesse ponto, passa-se do sentido de língua ao sentido de discurso, tendo em vista que o sujeito interpretante não busca o significado das palavras ou sua combinação (sentido de língua), mas seu sentido social (sentido de discurso).

E, para que a comunicação possa atingir a finalidade esperada pelo sujeito comunicante, é imprescindível que os parceiros estejam ligados pelo que Charaudeau chama de "contrato de comunicação" e que tenham um saber em comum; caso contrário, a comunicação estará vazia de significados para o sujeito interpretante. Não basta falarem a mesma língua, é preciso que se entendam culturalmente. O processo de comunicação é uma coconstrução de sentido, ou seja, não dispensa a participação de um dos sujeitos. Cada um tem a sua função dentro do processo. O texto, como resultante é, portanto, uma configuração de sentido. Cabe a nós, leitores, mergulharmos nas entrelinhas do texto, a fim ultrapassarmos o "sentido de língua".

\section{Que é ler?}

Ler um texto não é decodificar a mensagem. Segundo Dell'Isola (2001: 107), há processos decisivos que compõem o mecanismo da leitura. Num primeiro momento, o leitor decodifica o texto, para posteriormente compreender a informação explícita. Em seguida, seleciona o que considera mais significativo, de acordo com a sua visão de mundo, direcionando a sua leitura a uma determinada compreensão específica.

Pensares em Revista, São Gonçalo-RJ, n.2, p. 44 - 57, jan./jun. 2013 
O segundo momento consiste em ler as "entrelinhas" e integrar os dados do texto à própria experiência ou conhecimento do mundo. O leitor infere de acordo com seu conhecimento de mundo, que está enraizado em uma sociedade e em uma cultura. É nesse momento que ele consegue sair do nível da compreensão para ir mais além na leitura, ou seja, interpretar o que lê.

Após as inferências, o leitor é levado a se posicionar emocional e afetivamente diante do texto e a avaliar os fatos que lhe forem apresentados. $\mathrm{E}$, por último, aquilo que for significativo para o leitor fica retido na memória, podendo ser ativado em outros momentos, para o entendimento de situações comunicativas diversas.

É importante lembrar que, o aluno precisa perceber que "um texto permite muitas leituras, mas não infinitas. (...) compreender é produzir modelos cognitivos compatíveis preservando o valor-verdade". (MARCUSCHI, 2008, p. 257)

Por fim, vale destacar que, a leitura, sendo compromisso de todas as áreas (NEVES et alli, 2007) deve permitir que o sujeito interpretante não aprenda a repetir palavras, mas a dizer a sua palavra. Como afirma Citelli (1994, p. 50) apud Seffner (2007, p. 113),

É necessário ter claro que desenvolver uma competência para a leitura (da palavra) implica contribuir no sentido da formação de um cidadão mais pleno, que possa, criticamente, se assenhorar de um mecanismo tradicionalmente utilizado pela classe dominante. Tomar posse da palavra não para refazer o circuito da discriminação, mas para forçar espaços de libertação.

\section{Os signos na visão de Peirce}

A Semiótica pode ser definida como uma teoria geral dos signos. Segundo Santaella (2012, p. 5), a teoria semiótica nos permite

penetrar no próprio movimento interno das mensagens, no modo como elas são engendradas, nos procedimentos e recursos nelas utilizados. Permite-nos também captar seus vetores de referencialidade não apenas a um contexto mais imediato, como também a um contexto estendido, pois em todo processo de signos ficam marcas deixadas pela história, pelo nível de desenvolvimento das forças produtivas econômicas, pela técnica e pelo sujeito que as produz.

Pensares em Revista, São Gonçalo-RJ, n.2, p. 44 - 57, jan./jun. 2013 
Assim, neste estudo, como não analisamos apenas a linguagem verbal, auxilia-nos na leitura dos signos, a ciência Semiótica, criada pelo lógico e filósofo americano Charles Sanders Peirce desde o final do século XIX, tendo em vista que tal ciência fornece definições rigorosas do signo e do modo como os signos se apresentam.

Peirce (2010, p. 46), na sua obra Semiótica, conceitua signo da seguinte forma:

Um signo, ou representâmen, é aquilo que, sob certo aspecto ou modo, representa algo para alguém. Dirige-se a alguém, isto é, cria, na mente dessa pessoa, um signo equivalente, ou talvez um signo mais desenvolvido. Ao signo assim criado denomino interpretante do primeiro signo. O signo representa alguma coisa, seu objeto. Representa esse objeto não em todos os seus aspectos, mas com referência a um tipo de ideia que eu, por vezes, denominei fundamento do representâmen. (...)

Dependendo do modo como se estabelece a relação entre signo e referente - qualidade, existente ou lei -, para Peirce (2010, p. 63-76), um signo pode ser denominado ícone, índice ou símbolo:

a) ícone: é um signo cuja relação signo/objeto é de similaridade (semelhanças). Sugere ou evoca algo porque a qualidade que ele exibe se assemelha a outra qualidade. É a base da metáfora. Por exemplo, estátuas, imagens, quadros, onomatopeias etc.

b) índice: é um signo cuja relação signo/objeto é estabelecida de forma direta, real e causal. Sua relação é de contiguidade (pertence a, a partir de, causa/efeito). É a base da metonímia. São exemplos de índice a pegada, a impressão digital, a fumaça (fogo), a nuvem escura (chuva), o chão molhado (choveu), o termômetro, o cata-vento, o relógio etc.

c) símbolo: é um signo cuja relação signo/objeto não é imediata, pois não há necessariamente similaridade ou contiguidade com o objeto, sendo quase sempre tomado de forma arbitrária, só significando dentro de uma convenção estabelecida pela sociedade. São exemplos de símbolos os sinais de trânsito, 
as placas indicativas, aliança no dedo anular (= compromisso), veste negra (= luto) e, principalmente, o signo linguístico.

As relações sígnicas são importantes para o estudo da linguagem das capas de revista, pois as capas combinam mais de um tipo de signo - a palavra, signo verbal caracterizado pela arbitrariedade e pela linearidade, e da imagem, signo icônico caracterizado pela similaridade e pela superficialidade. Por exemplo, a foto de uma mulher loira é ícone quando tomada como imagem, mas é símbolo quando representa "glamour", "beleza"... Produtos como carro ou cartão de crédito podem ser ícones quando imagens, mas símbolos quando representam ideias abstratas como "status", "sofisticação", "potência" (carro) no sentido semântico e no conotativo - quando apela para a virilidade. Como afirma Feres (2011, p. 56),

(...) Desde as cores do ambiente à expressão fisionômica das personagens, os signos icônicos podem carregar uma relação de semelhança com o objeto representado, num sentido primeiro, "literal", como também relações aproximativas, por meio de metonímias (com os índices), ou de metáforas, numa "dupla similaridade", num sentido "conotativo". E essa possibilidade de produção de sentido depende do cálculo do não dito, das operações inferenciais, da intertextualidade e de outras estratégias de leitura, tanto quanto na interpretação do signo verbal.

Feres (ibidem, p. 57) chama ainda atenção para a falsa transparência das imagens. Segundo a autora,

(...) as imagens trazem, aparentemente, um caráter universal, visto que o homem as produz desde a pré-história até nossos dias - e a similaridade entre esses elementos e a realidade que representam induz a esse engano. Isso traz a impressão de que a leitura desses elementos seja "natural", ou "automática"; (...) o signo icônico atrai o leitor pela aparente "facilidade" de leitura, mas está, o tempo todo, exigindo uma outra leitura, mais profunda, sempre ativadora do plano discursivo/situacional, para permitir sua interpretação. São ícones incessantemente transformados em índices e símbolos, que precisam ser, além de reconhecidos/compreendidos, interpretados.

$\mathrm{Na}$ verdade, as capas de revista constituem um enunciado recortado e selecionado da realidade, revelando o viés de seu produtor. 


\section{0 trocadilho com a palavra "polvo" nas capas da Veja}

As capas de revista são um gênero textual, ou seja, são textos materializados que encontramos em nossa vida diária e que apresentam características sócio-comunicativas definidas por conteúdos, propriedades funcionais, estilo e composição característica.

Os elementos verbais que compõem a capa de uma revista são, normalmente, manchete principal (ou título), manchetes secundárias, subtítulos e até supratítulos que conduzem a leitura da manchete, nome da revista, nome da editora responsável com logomarca, data de publicação, número da edição, site e valor do exemplar. Além desses elementos verbais, as capas de revista também apresentam elementos não-verbais, tais como imagem, diagramação (layout), cores predominantes no plano de fundo, qualidade do papel, formato e cores das letras, formatação das chamadas e das imagens.

$\mathrm{Na}$ manchete principal e nas manchetes secundárias, normalmente, há sempre uma palavra ou expressão que indica ao leitor a que área temática os textos da revista fazem referência. Esse destaque nas manchetes tem por objetivo situar o leitor quanto ao assunto que será abordado, como também dar maior ênfase e dramaticidade ao tema em questão.

A manchete principal, em geral, seguida por um subtítulo, é aquela que ocupa grande parte da capa, destacada por elementos gráficos (letras grandes e cheias, cores que se destacam do restante da capa) e icônicos. Além da manchete principal que destaque o assunto de maior ênfase da edição, a maioria das capas também traz manchetes secundárias sobre outros assuntos. Essas manchetes secundárias, em geral, localizam-se nas laterais ou no alto da página, com letras pequenas e sem muito destaque, tendo em vista que Ihes é dada menor ênfase em relação à principal. Segundo Scalzo (2003, p. 62),

Uma boa revista precisa de uma capa que a ajude a conquistar leitores e os convença a levá-la para casa. Capa é feita para vender revista. Por isso, precisa ser o resumo irresistível de cada edição, uma espécie de vitrine para o deleite e a sedução do leitor. 
Nesse sentido, as capas representam a embalagem das notícias, formando antecipadamente a opinião dos leitores a respeito dos assuntos que serão abordados dentro da revista. Grande parte do público leitor não tem acesso às reportagens anunciadas nas revistas de modo integral, ou seja, é apenas o leitor de banca. Assim, a simples exposição dos elementos sígnicos na capa pode transmitir informações e direcionar a interpretação dos fatos. Tal exposição altera o que seria a mera informação, ou seja, a objetividade proposta nessa esfera de circulação de notícias.

Passemos à análise.

Fig. 1

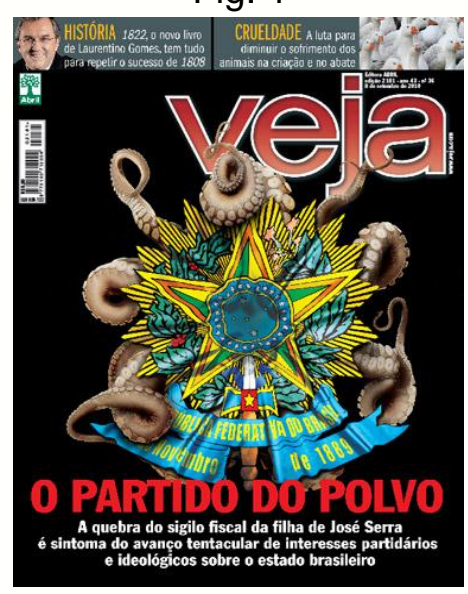

(Revista Veja - 08/09/2010)

Fig. 2

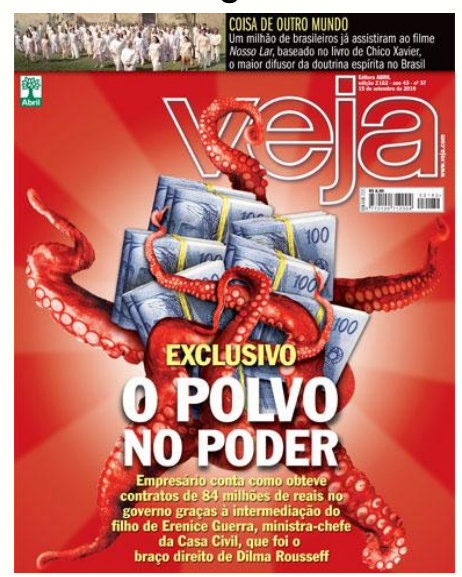

(Revista Veja - 15/09/2010) 
Fig. 3

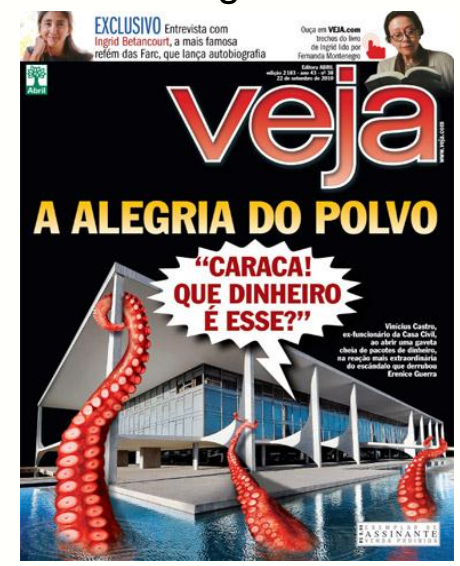

(Revista Veja - 22/09/2010)

Nas três capas, a revista Veja faz um trocadilho com a semelhança entre as palavras "polvo" e "povo". O trocadilho é uma figura de estilo e constitui um recurso retórico mais utilizado em textos humorísticos e publicitários. No entanto, tal recurso foi utilizado em um gênero textual, normalmente, conhecido pela objetividade. O trocadilho nessas capas é intencional, tendo em vista que o sujeito comunicante (o produtor da capa) aproveita a sonoridade similar entre as palavras para expressar sentidos. Mas, por que a palavra "polvo"?

O polvo é um molusco marinho. Possui oito braços com fortes ventosas dispostas à volta da boca. O polvo tem um corpo mole, sendo um animal invertebrado. Como meios de defesa, esse molusco possui a capacidade de largar tinta e de se camuflar e a autonomia dos braços.

Todos os polvos são predadores, vorazes e caçam com os braços e matam com o bico. Para auxiliar a caça, os polvos desenvolveram a visão binocular e olhos com estrutura semelhante à do órgão de visão do ser humano, que tem percepção de cor.

Além dessas características, o polvo é conhecido não só como um animal inteligente, criativo e flexível, mas também como aquele que representa a estratégia, o sigilo e o poder da razão.

Assim, a relação nas capas da revista Veja não é à toa. No entanto, um pouco contraditória, pois, num primeiro momento, o leitor identifica o trocadilho 
com a palavra "povo", levando-o a pensar que o "povo está no poder", que "o povo está alegre", por exemplo. Porém, não é o povo que está bem, mas algumas pessoas ligadas à política. Todas as três capas criticam o PT, Partido dos Trabalhadores, conhecido como o partido do povo. Aqui, o povo é a vítima, aquele que está sendo trapaceado.

Na primeira capa, "O partido do povo", lê-se abaixo dessa manchete o seguinte: "A quebra do sigilo fiscal da filha de José Serra é sintoma do avanço tentacular de interesses partidários e ideológicos sobre o estado brasileiro."

A revista critica o governo de Lula, levando a crer que pessoas ligadas ao ex-presidente violaram o sigilo fiscal da filha do tucano José Serra, na época, opositor de Dilma Rousseff na corrida pela Presidência da República. Segundo a revista, os documentos da filha de Serra chegaram "a uma mansão em Brasília onde funciona um dos comitês de campanha da candidata petista Dilma Rousseff". (p. 74) Ainda segundo a revista, esse tinha sido apenas "o episódio mais recente do contínuo processo de agressão aos direitos individuais e aos princípios elementares da democracia".

A oposição da revista ao governo Lula é tão contundente que chega a afirmar: "O desprezo pelas instituições é uma marca que será deixada pelo governo Lula. Aparelhamento, cooptação de servidores e sindicalistas, favorecimento a aliado e perseguição a adversários passaram a ser procedimentos rotineiros em órgãos públicos, que deveriam zelar pelo bom funcionamento do aparelho estatal. No poder, o PT colocou o estado a serviço do governo e do partido." (p. 78) E a crítica continua em mais outras páginas. São dezesseis páginas destinadas a criticar o governo e, principalmente, a figura do presidente da época, Lula.

É interessante também observar as manchetes das reportagens relacionadas à capa: "O Estado a serviço do partido" (p. 72-80), "O partido do polvo" (p. 82-86) e "Mister M na fazenda" (p. 87). Esta última traz em destaque o ministro da fazenda Guido Mantega vestido de mágico e de sua cartola saem notas de cem e cinquenta reais. Segundo a Veja, o "governo usa manobras contábeis para tirar dinheiro da cartola e continuar gastando." (p. 87) 
A edição seguinte da Veja - "O polvo no poder" também traz uma série de reportagens que têm como objetivo atacar o então presidente da República Lula. Segundo a revista, "próximo ao gabinete presidencial, no Palácio, o filho da ministra Erenice Guerra, chefe da Casa Civil, comanda um esquema de lobby que conta com a ajuda da mãe para atrair empresários interessados em contratos com o governo". (p. 76)

Tentando se defender, na sessão "Carta ao Leitor", a revista publica o seguinte comentário a respeito da reportagem relacionada à capa: "A publicação da reportagem a vinte dias do primeiro turno das eleições fará brotar acusações de que o objetivo é prejudicar a candidata oficial, Dilma Rousseff. São especulações inevitáveis. Mas quais seriam as opções? Não publicar? Só publicar depois das eleições? Essas não são opções válidas no mundo do jornalismo responsável, a atividade dedicada à busca da verdade e sua revelação em benefício do país." (p. 13)

E, a terceira edição com a palavra "polvo" é de 22 de setembro - "A alegria do polvo". Nessa edição, a Veja critica funcionários do Planalto que receberam propinas dentro da Casa Civil, a metros da sala da então ministra Dilma Rousseff e a um andar do gabinete do presidente Lula. Ainda nessa edição, a revista traz outras reportagens contra o governo - “'Ideias são mais letais que armas"” (p. 78): acusa o PT de querer calar a imprensa e "Como varrer escândalos para debaixo do tapete" (p. 84-87): acusa o governo de minimizar o crime de violação do sigilo dos tucanos e usar instituições para abafá-lo.

As capas dessas três edições parecem mais uma peça publicitária. A imagem do "polvo" abraçando o brasão e maços de dinheiro e se deleitando nas águas do Planalto é a própria imagem do terrorismo eleitoral. Na primeira e terceira capas, o preto é a cor que predomina. Na segunda, o vermelho. $\mathrm{O}$ preto é a cor, normalmente, atribuída ao luto, ao medo, ao terror. O vermelho, aqui, representa a guerra, a vergonha.

A relação estabelecida entre a imagem do "polvo" e o governo é um ícone, tendo em vista que sugere algo - flexibilidade, agilidade e sigilo nas transações, voracidade - porque a qualidade que ele - o polvo - exibe - oito 
braços grandes com ventosas, camuflagem, por exemplo - se assemelha a outra qualidade - a qualidade que alguns políticos apresentam de camuflar transações inidôneas, de agir com voracidade - nesse caso, em tudo que envolve dinheiro, não se importando com os outros. Já as cores - vermelho e preto - funcionam como índice de que a situação política no Brasil, na época, não era nada boa: roubo, trapaça, ações sigilosas e fraudulentas.

Como então afirmar que o gênero "capa de revista" é objetivo?

\section{Conclusão}

As revistas, como qualquer outro periódico, são um produto feito para informar e vender. E, nesse sentido, ser só objetivo nem sempre é suficiente para atrair o leitor e possível comprador.

As análises das capas de revista revelaram que esse gênero textual não é objetivo; pelo contrário, traduz a ideologia da revista. Se o leitor não estiver atento, pode interpretar os fatos a partir da visão que a revista quer passar. Além disso, a capa tem por objetivo chamar a atenção, daí o exagero nas imagens, nas cores, no tamanho das letras etc. É preciso não ser leitor apenas de capas, mas de toda a revista, a fim de não ser levado a fazer uma interpretação errada dos fatos.

$\mathrm{E}$, nesse sentido, a inserção do discurso midiático na escola é imprescindível. Não faz sentido o professor continuar planejando suas aulas apenas com o apoio do livro didático. O aluno precisa ser instigado a buscar e resolver novos desafios.

O ensino de língua portuguesa não deve ser feito de modo "engessado", isto é, por meio de práticas de ensino cristalizadas, que privilegiam o aspecto gramatical em detrimento da leitura e da interpretação crítica. O aluno precisa entender que a língua é vida e que as possibilidades de combinação dos signos são inúmeras, o que possibilita produzir um texto extremamente criativo.

Trabalhar com diferentes gêneros textuais, dentre eles, as capas de revista, leva o aluno a refletir sobre a própria sociedade em que está inserida. As capas de revista, normalmente, enfocam temas atuais, de grande 
repercussão. Cabe ao professor fazer da escola uma parte da sociedade, e não um mundo sem significados com a vida do aluno.

\section{Referências bibliográficas}

CHARAUDEAU, P. Discurso das mídias. São Paulo: Contexto, 2006.

Uma teoria dos sujeitos da linguagem. In: MARI, H. et al. Análise do discurso: fundamentos e práticas. Belo Horizonte: Núcleo de Análise do Discurso - FALE / UFMG, 2001, p. 23-37.

Análise do discurso: controvérsias e perspectivas. In: MARI, $\mathrm{H}$. et al.(Org.). Fundamentos e dimensões da Análise do Discurso. Belo Horizonte: Carol Borges - Núcleo de Análise do Discurso. Fale - UFMG, 1999, p. 27-43.

DELL'ISOLA, R. L. P. Leitura: inferências e contexto sociocultural. Belo Horizonte: Formato Editorial, 2001.

FERES, B. dos S. Leitura, fruição e ensino com os meninos de Ziraldo. Niterói: Editora UFF, 2011.

MARCUSCHI, L. A. Produção textual, análise de gêneros e compreensão. São Paulo: Parábola Editorial, 2008.

NEVES, I. C. B. et al. (Org.) Ler e escrever: compromisso de todas as áreas. 8. ed. Porto Alegre: Editora da UFRGS, 2007.

PEIRCE, C. S. Divisão dos signos; Ícone, índice e símbolo. In: Semiótica. 4. ed. São Paulo: Editora Perspectiva, 2010, p. 45-76.

SANTAELLA, L. Semiótica aplicada. São Paulo: Cengage Learning, 2012.

SCALZO, M. Jornalismo em revista. São Paulo: Contexto, 2003.

SEFFNER, F. Leitura e escrita na história. In: NEVES, I. C. B. et al. (Org.) Ler e escrever: compromisso de todas as áreas. 8. ed. Porto Alegre: Editora da UFRGS, 2007.

\section{Revistas}

O partido do polvo. In: Revista Veja. São Paulo: Abril, 08 de setembro de 2010. Disponível em: http://veja.abril.com.br/busca/resultadocapas.shtml? Vyear=2010. Acesso em dezembro de 2012. 
O polvo no poder. In: Revista Veja. São Paulo: Abril, 15 de setembro de 2010. em:

http://veja.abril.com.br/busca/resultadocapas.shtml? Vyear=2010. Acesso em dezembro de 2012.

A alegria do polvo. In: Revista Veja. São Paulo: Abril, 22 de setembro de 2010. Disponível em:

http://veja.abril.com.br/busca/resultadocapas.shtml? Vyear=2010. Acesso em dezembro de 2012.

Artigo recebido em: 25 de março de 2013

Artigo aprovado em: 30 de junho de 2013

\section{Sobre a autora:}

Doutorado em Língua Portuguesa pela Universidade Federal Fluminense (2009). 